\section{From Spain*}

\author{
E Lience
}

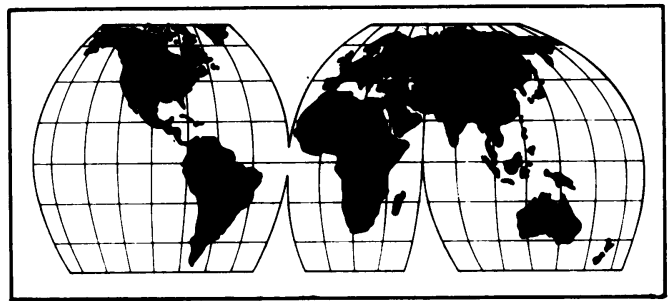

Members of the Sociedad Española de Reumatología have received a wide ranging report analysing the main aspects of the society, including its administration and the financing of its activities. The report was prepared by the president, Dr P Barceló, and the board of directors with advice from Andersen Consulting.

The Sociedad Española de Reumatología, in a similar way to other European medical societies, has been developing its activities. With the progressive increase in the number of members and increases in the complexity of the programmes that the society can design, it is obvious that the current organisational structure of the society could become insufficient. The report outlines the following possible requirements: $(a)$ a full time manager responsible for the financial organisation of the society, development of the policies defined by the board of directors, promotion of the society, and operational direction; and $(b)$ a full time secretary responsible for the organisation of courses and meetings in addition to secretarial and support tasks-the secretary would report directly to the manager. Although the creation of these two professional posts would initially increase the costs of the society, the performance of the organisation would improve and the ability to obtain a greater income would be enhanced. It is considered that the Sociedad Española de Reumatología should have an administrative structure similar to that of the British Society for Rheumatology, allowing its management to become more efficient.

Several methods of increasing the income of the Sociedad Española de Reumatología are analysed in the report; an increase in income will lead to an increase in the activities of the society. There are several procedures which could produce effective financial management with positive and favourable results.

The journal Revista Española de Reumatología began a new era in 1991 with the publication of 10 issues a year instead of six. Seven issues with the usual contents of the journal-that is, editorials, original papers, case reports, reviews, and letters to the editor-will appear; one issue will publish abstracts of all the papers accepted for the annual meeting of the society, and two issues will be monographs in an attempt to begin a collection of publications under the auspices of the Sociedad Española de Reumatología.

The increase in the frequency of publication of the journal has led to a remodelling of the structure of the journal in such a way that the editorial board now consists of an editor, an executive editor, an editorial secretary, and three associated editors. The journal has a committee of referees and each paper is reviewed by two or three referees. Everybody is working hard to improve the quality of the journal. One of the most important problems is that the best Spanish papers are submitted to English language journals with a high impact factor and for that reason papers submitted to Revista Española de Reumatología do not realistically reflect the state of rheumatological research in Spain. The impact index places Revista Española de Reumatologia below the competitive English language journals.

A topic often discussed is whether to publish the journal in Spanish or English to reach a wider audience and to attract higher quality original papers. At present, we believe that the journal must be published in Spanish and we need to continue to publish 500 issues with complete English translations of the original papers.

A small format informative bulletin (Boletin Informativo) is published five times a year by the Sociedad Española de Reumatología; this bulletin gives a closer and more informal contact between members of the society.

Several years ago, a number of work committees were created by the Sociedad Española de Reumatología; these are specialised in particular fields which are becoming the key infrastructure for the functioning of the society. These are described in the following.

\section{Education committee}

It has been proposed to give short and average duration grants for members to attend Spanish or foreign rheumatology units. In most instances, the training of an interested rheumatologist in a particular field may be improved by attending a Spanish centre with adequate facilities. In other instances, to give a grant for a short stay (no more than six months) in a foreign centre may give more favourable results. At present, the Sociedad Española de Reumatología cannot support long stays abroad.

There are plans to hold one or two courses a year for residents; such courses could take place 
over a weekend or related to the annual meeting of the Sociedad Española de Reumatología.

It is important to allow representatives of rheumatology schools to meet during annual meetings of the society to exchange opinions and establish common standpoints for action. It will be interesting to promote associations of health workers related to rheumatology; these associations would be independent of the Sociedad Española de Reumatología.

Residents of community and family medicine attend hospital units of rheumatology during their training. It would be beneficial if programmes were improved to increase the quality of their education.

\section{Editorial committee}

Immediate projects are: $(a)$ to edit a nomenclature of the rheumatic diseases-this was published in February 1992 by the Sociedad Española de Reumatología; (b) to have a photographic library-that is, a collection of educational slides that could be supplied to members of the society; and $(c)$ to publish a methodology course for rheumatologists; the text is already well advanced and will appear in the second half of 1992.

\section{Research committee}

Rheumatology research in Spain should be promoted by multicentre studies; these are not difficult to carry out based on collected experience. Thus small units should combine to carry out major important projects. In the future, basic research and research applied to rheumatology jobs must receive grants; rheumatological research in Spain is currently rather deficient because most rheumatologists are dedicated to patient care. This committee coordinates its work with the education committee with respect to grant programmes.

\section{Paediatric rheumatology committee}

Of recent creation, this committee is preparing a survey of paediatric rheumatology in Spain and brought together all interested rheumatologists at the 1991 annual meeting. Its most important aims are to develop a common database, to conduct epidemiological studies, to sponsor international meetings, to create a specific section of paediatric rheumatology in the Revista Española de Reumatología, and to publish monographs in the journal-the first of which appeared in October 1991. Although the results of the survey have not yet been analysed, there are at least six groups interested in paediatric rheumatology.

\section{International relations committee}

It is considered important to develop relations between the Sociedad Española de Reumatología and the EULAR and the ILAR, and with neighbouring countries; some projects are being carried out to achieve this. An important way to promote international relations will no doubt be with the XVIIth ILAR congress that will take place in Barcelona, 4-10 July 1993.

Spanish participation in the annual general meeting of the British Society for Rheumatology is high; this meeting is considered to be highly educational and exciting for young rheumatologists. The Sociedad Española de Reumatología is interested in promoting the participation of members in this meeting. The British Society for Rheumatology is considering a change in the date and place of future annual general meetings, which may diminish the number of Spanish rheumatologists attending as they usually go to the British meeting in autumn or winter and hold the Spanish meeting in the spring; it has also been suggested that the annual general meeting may not be held in London; Spanish rheumatologists generally find it more attractive to go to London than any other city.

The Sociedad Española de Reumatología is very interested in developing relations with Latin American countries through the Comité Latino of the American College of Rheumatology and the Comite Iberoamericano de Reumatología.

\section{Patient care committee}

A plan for clinical rheumatology has been developed but not yet published. Catalonian rheumatologists have finished a clinical rheumatological plan for Catalonia; this autonomous community has a population of six million and the plan considers that the ideal ratio would be one rheumatologist for every 50000 inhabitants; this ratio would allow the provision of good rheumatological care in the community.

The annual meeting of the Sociedad Española de Reumatología was held in Madrid on 9-10 May 1991. Dr J Rotés-Querol gave a lecture on vertebral ankylosing hyperostosis and there was a session devoted to metabolic bone disease as well as poster presentations and submitted papers. The Sociedad Española de Reumatología congress, which takes place every two years, will be held in San Sebastián from 2 to 6 June 1992; the programme is being prepared. 